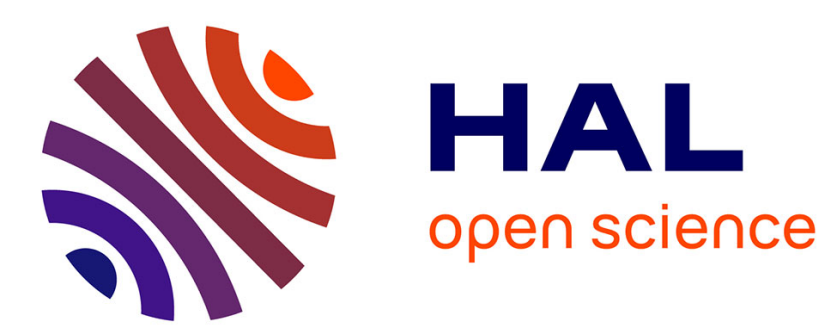

\title{
Characterization of Carbon Supported Pt/Ru Alloy Particles Using EXAFS Spectroscopy
}

\author{
K. Pandya, E. Anderson, D. Sayers, W. O'Grady
}

\section{To cite this version:}

K. Pandya, E. Anderson, D. Sayers, W. O'Grady. Characterization of Carbon Supported Pt/Ru Alloy Particles Using EXAFS Spectroscopy. Journal de Physique IV Proceedings, 1997, 7 (C2), pp.C2-955C2-956. 10.1051/.jp4:1997299 . jpa-00255373

\section{HAL Id: jpa-00255373 https://hal.science/jpa-00255373}

Submitted on 1 Jan 1997

HAL is a multi-disciplinary open access archive for the deposit and dissemination of scientific research documents, whether they are published or not. The documents may come from teaching and research institutions in France or abroad, or from public or private research centers.
L'archive ouverte pluridisciplinaire HAL, est destinée au dépôt et à la diffusion de documents scientifiques de niveau recherche, publiés ou non, émanant des établissements d'enseignement et de recherche français ou étrangers, des laboratoires publics ou privés. 


\title{
Characterization of Carbon Supported Pt/Ru Alloy Particles Using EXAFS Spectroscopy
}

\author{
K.I. Pandya, E.B. Anderson*, D.E. Sayers and W.E. O'Grady** \\ Department of Physics, North Carolina State University, Raleigh, NC 27695, U.S.A. \\ * PSI Technology Company, 20 New England Business Center, Andover, MA 01810, U.S.A. \\ ** Code 6170, Naval Research Laboratory, Washington, DC 20375, U.S.A.
}

\begin{abstract}
Abatract. Pt/Ru alloys are used for electroxidation of methanol in direct methanol fuel cells. Their catalytic activity strongly depends upon the structure and composition of the alloy particles. We have investigated the structure of PURu alloy particles supported on high surface area carbon for three different compositions, namely Pt:Ru,8.5:1.5, 1:1 and 1.5:8.5. The samples were prepared by impregnating the carbon with salt solutions of the two metals followed by reduction to the alloy. The total metal loeding was 10 wt\%. The $\mathrm{Pt} \mathrm{L}_{3}$ and Ru K EXAFS experiments were carried out at $\mathrm{LN}_{2}$ temperature on beamline X1 1A of NSLS. The data were analyzed to get consistent structural parameters from both the Pt and Ru EXAFS. The results show that the metals are completely alloyed and the average Pt-Ru distance is $2.70 \AA$. Difficulties which arose in the data analysis will be discussed.
\end{abstract}

\section{Introduction}

The alloys of platinum and ruthenium are known to be some of the best catalysts for the direct electrochemical oxidation of methanol to $\mathrm{CO}_{2}$. In order to understand and improve their catalytic activity it is necessary to determine the structure and composition of the alloy particles. We have undertaken a detailed study of the carbon supported Pt/Ru alloys. Our in-situ XAS measurements (Pt I 3 and Ru K edges) showed that there is a significant modification of the alloy structure in the methanol oxidation potential regime [1,2]. However, the analysis of these in-situ EXAFS data was found to be highly complicated. Although we were able to obtain qualitative information mainly from the radial structure functions and near edge spectra, it was not possible to get consistent structural parameters from the usual EXAFS fitting procedures. In fact, other groups have also experienced similar difficulties and their EXAFS analysis is carried out in highly constrained manners [3]. This could be partly due to the complexity of the in-situ chemistry of the small supported particles. In order to avoid this complexity we undertook an ex-situ XAS study of large Pt/Ru alloy particles of varying composition that would help us understand the interplay between the Pt and Ru.

\section{Experimental}

Carbon supported Pt-Ru alloys with three different compositions namely Pt:Ru,8.5:1.5, 1:1 and 1.5:8.5 were prepared using techniques developed at PSI. The support material carbon was sequentially impregnated with a solution of chloroplatic acid and ruthenium chloride. The precursor is reduced in hydrogen at an elevated temperature. The particles were given a final heat treatment at $900^{\circ} \mathrm{C}$. The XAS measurements were performed at the National Synchrotron Light Source (NSLS) on beamline X11A using a Si(111) double crystal monochromator and gas flow ionization chambers to monitor the intensities of the incident and transmitted X-rays.

\section{Data Analysis and Results.}

Reference Data: The Pt-Pt, Pt-Ru, Ru-Ru and Ru-Pt reference spectra were calculated using the program FEFF 5.03 developed by J. Rehr [4]. The EXAFS data for the Pt foil and Ru metal were fitted using the theoretical references to obtain the values of $S_{0}{ }^{2}$. Next, FEFF was used to calculate the back scattering amplitude, $f(\pi, k)$, and the phase functions, $\Phi(k)$, for the Pt-Pt, Pt-Ru, Ru-Ru and Ru-Pt interactions. These are shown in Figures 1 and 2, respectively. The backscattering amplitudes of $P t$ and $R u$ are significantly different. In the $k$-range extending up to $k=13 \AA^{-1}$ the backscattering amplitude for $R u, f_{R u}(\pi, k)$, is much higher than the backscattering amplitude for Pt, $f_{p t}(\pi$, $k$ ), while for $k>13 \AA^{-1}, \mathrm{f}_{\mathrm{Pt}}(\pi, k)$ dominates. Above $k=6 \AA^{-1}, \mathrm{f}_{\mathrm{Pt}}(\pi, k)$ shows two maxima and a minimum. In contrast, $\mathrm{f}_{\mathrm{Rg}}(\pi, k)$ shows only one maximum and it decays rapidly. The phase functions, $\Phi(k)$, for the Pt-Pt, Pt-Ru, Ru-Ru and Ru-Pt are shown in Figure 2 . Interestingly, the phase difference between $\Phi_{\mathrm{Pt}-\mathrm{pt}}(k)$ and $\Phi_{\mathrm{Pt}-\mathrm{Ru}}(k)$ is about $\pi$ radian in the range of $6 \AA^{-1}<k<11 \AA^{-1}$. This would give rise to destructive interference between the Pt-Pt and Pt-Ru EXAFS contributions. This is also the case for the Ru-Ru and Ru-Pt contributions. As the backscattering amplitudes of $\mathrm{Pt}$ and $\mathrm{Ru}$ are distinctively different, the destructive interference is expected to effect an EXAFS spectrum differently in various $k$-ranges (e.g. low- $k$ vs. high $k$ ). For example, consider the $\mathrm{Pt}_{3}$ EXAFS for a system containing equal numbers of Pt and Ru neighbors having the same bond distances. For the Pt EXAFS, the $\chi_{\mathrm{PP}-\mathrm{Ru}}(k)$ is expected to dominate up to $k$ $=13 \AA^{-1}$. Beyond that $\chi_{\mathrm{Pt}-\mathrm{Pt}}(k)$ will dominate because $\mathrm{f}_{\mathrm{Pt}}(\pi, k)$ is greater than $\mathrm{f}_{\mathrm{Rm}}(\pi, k)$ for $k>13 \AA^{-1}$.

Data Processing: The EXAFS function $\chi(k)$ was separated from the experimentally measured absorption spectrum using the standard procedures. The $\mathrm{Pt}_{3}$ and Ru K odge radial structure functions (RSFs) for the alloy samples are shown in the figures 3 and 4, respectively. The RSFs are significantly different from each other indicating that the structure strongly depends upon the composition. The effect of the 
destnuctive interference at the $P t L_{3}$ edge and $R u K$ edge is clearly seen in the RSFs. The amplitudes of the Pt $L_{3}$ EXAFS signal (seen as the intensity of the first peak in the RSF) decrease in the following order: $\mathrm{Pt}_{8,5} \mathrm{Ru}_{1,5}>\mathrm{Pt}_{1,5} \mathrm{Ru}_{8.5}>\mathrm{Pt}_{5.0} \mathrm{Ru}_{5.0}$. This could mean that the particles are largest for the $\mathrm{Pt}_{\mathrm{Q}} \mathrm{Ru}_{15}$ sample, and the particle size follow the same trend as the EXAFS amplitude. However, this observation is not supported by the Ru EXAFS. At the Ru edge, the intensity of the $\mathrm{Ru}_{8,5} \mathrm{Pt}_{15}$ (same as $\mathrm{Pt}_{1} \mathrm{Ru}_{85}$ ) sample is the highest indicating largest particles. This contradictory observation indicates that it is necessary to analyze both Pt and Ru EXAFS in order to get consistent results. The peak heights can not be used to judge the coordination numbers (and hence the particle size). Interestingly, the amplitude of the EXAFS signal at both the $\mathrm{Pt}$ and $\mathrm{Ru}$ edges for the $\mathrm{Pt}_{5.0} \mathrm{Ru}_{5.0}$ sample is the lowest. For this sample composition (50/50) the possibility of having equal numbers of Pt and Ru neighbors is very high. Hence, the extent of destructive interference is expected to be a maximum at both the $\mathrm{Pt}$ and Ru edge EXAFS. The structural parameters for the Pt-Pt $(\mathrm{Ru}-\mathrm{Pt})$ and $\mathrm{Pt}-\mathrm{Ru}(\mathrm{Ru}-\mathrm{Ru})$ contributions were found to be highly correlated because of their phases as discussed above. The preliminary analysis showed that the metals are completely alloyed and the average Pt-Ru bond distance is $2.70 \AA$.

\section{Summary}

It is shown that the EXAFS analysis of the PtRu system is complicated. The difficulties in the analysis is due to the phase functions of the Pt and Ru. We recommend the use of phase corrected Fourier transformation coupled with EXAFS analysis of both the Pt and Ru EXAFS in the largest possible data range to obtain consistentreliable results. The analysis of the in-situ data is further complicated by the presence of the other adsorbed species from the electrolyte solutions. Additionally, the Pt-Pt and Pt-O interactions are in phase in the low $k$ region. Thus it is extremely difficult to obtain quantitative information for the various contributions.

This work was sponsored by the Office of Naval Research and ARPA. The beamline XIIA and the NSLS are supported by the U.S. Department of Energy, under contract No. DE-FG05-89ER45384 and DE-AC02-76CH00016.

\section{Reference:}

[1] O'Grady W.E., Swider K.E., Pandya K.I. and Kowalak A.D.,Extended Abstract, Electrochem. Society, Vol 95-1, p744 (1995)

[2] Swider K.E., Pandya K.I., Kowalak A.D.and O'Grady W.E., Extended Abstract, Electrochem. Society, Vol 95-1, p742 (1995)

[3] McBreen J. and Mukerjee S., J. Phys. Chem., 142, 10, p3339 (1995)

[4] Rehr J., Albers R.C., and Zabinsky S.I., Phys. Rev. Lett., 69, 3397 (1992)

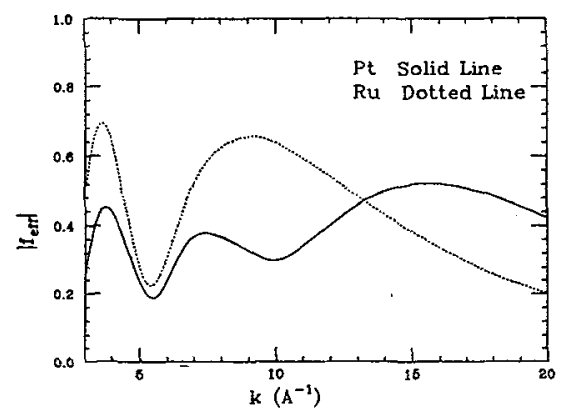

Figure 1 FEFF Calculated Bacckscattering Functions

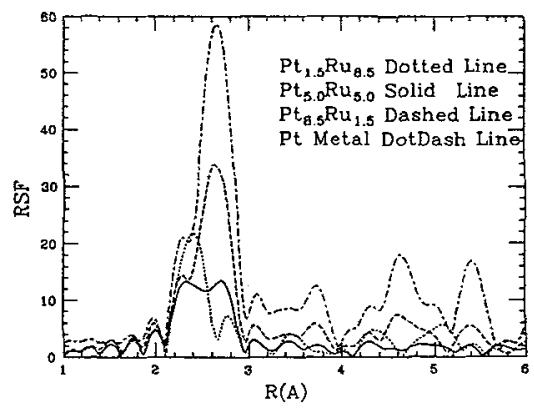

Figure 3 Pt-edge Radial Structure Functions FT $\left(\mathbf{k}^{3}, \Delta \mathbf{k} 3-18\right)$

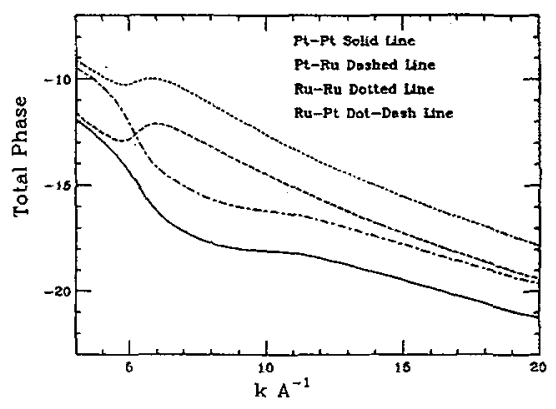

Figure 2 FEFF Calculated Phase Functions

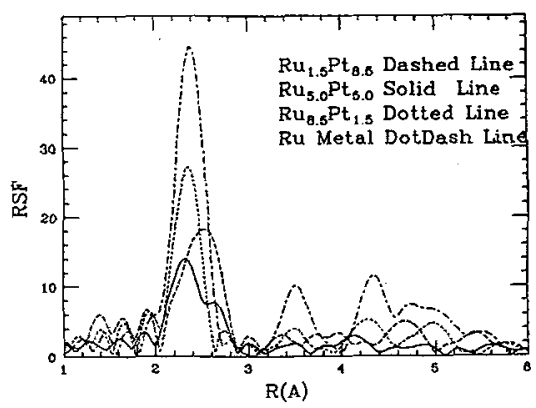

Figure 4 Ru-edge Radial Structure Functions $\mathrm{FT}\left(\mathrm{k}^{3}, \Delta \mathrm{k} 2.7-18\right)$ 